\title{
PENGEMBANGAN PEMBELAJARAN BERBASIS BLENDED LEARNING PADA MATA KULIAH PEMROGRAMAN KOMPUTER (STUDI KASUS: UNISDA LAMONGAN)
}

\author{
Nisaul Barokati ${ }^{1)}$, Fajar Annas ${ }^{2)}$ \\ ${ }^{1}$ Jurusan Pendidikan Bahasa Indonesia, Fakultas Keguruan dan Ilmu Pendidikan \\ ${ }^{2}$ Jurusan Akuntansi dan Manajemen, Fakultas Ekonomi \\ Universitas Islam Darul Ulum Lamongan \\ Jl. Airlangga 3 Sukodadi Lamongan, 62253 \\ Telp : (0322) 390497, Fax : (031) 390929 \\ E-mail: nisaul.seliro@gmail.com
}

\begin{abstract}
Information Technology is one of the biggest contribution to modern world. Meanwhile, learning is an activity which involving several persons with knowledge acquisition as their main purpose. ELearning become one of the solution towards globalization either for students or teachers in order to minimize time and distance in learning process. Learning outcome can be achieved by several sequential processes with certain stages in those processes. In this study, a spesific course in a university (UNISDA) environment was taken as an example of E-Learning. Computer Programming which has the closest relationship towards Information Technology was chosen to be implemented first to build in one of ELearning Modules. The result shows that E-Learning can create different and better learning atmosphere compared to before E-Learning implementation.
\end{abstract}

\section{Abstrak}

Teknologi Informasi merupakan salah satu tolak ukur terbesar bagi tingkat modern di dunia. Sedangkan, proses pembelajaran adalan proses yang melibatkan beberapa orang dengan tujuan untuk memperoleh pengetahuan. E-Learning menjadi salah satu solusi dalam menghadapi kemajuan teknologi dengan tetap mempertimbangkan kaidah-kaidah yang terdapat dalam proses pembelajaran. E-Learning juga memiliki kelebihan untuk meminimalkan efek dari waktu dan jarak yang selalu muncul dalam proses perolehan pengetahuan. Pada penelitian ini, mata kuliah Pemrograman Komputer dijadikan salah satu uji coba pertama dalam implementasi E-Learning. Mata kuliah Pemrograman Komputer ini telah diterapkan pada salah satu universitas di Indonesia (UNISDA) dan terdapat beberapa perbedaan yang lebih baik bila dibandingkan dengan sebelum implementasi E-Learning.

Kata kunci: pembelajaran, hasil belajar, blended learning

\section{PENDAHULUAN}

Dewasa ini, kita telah memasuki masa yang disebut sebagai abad pengetahuan (knowledge age). Tahapan tonggak sejarah peradaban manusia tersebut dilalui dengan belajar sepanjang hayat. Pada abad pengetahuan teknologi utama yang menjadi landasannya adalah komputer (Wasis, 2010). Hakekat pembelajaran merupakan suatu kegiatan yang melibatkan seseorang dalam upaya memperoleh pengetahuan, keterampilan dan nilai positif dengan memanfaatkan berbagai sumber untuk belajar (Chepi, 2003). Hasil belajar diperoleh melalui proses atau tahapan tertentu, dan pebelajar mengkonstruksi pengetahuan tidak secara spontan atau instant, namun bertahap. Hasil belajar yang diperoleh dari kegiatan belajar membutuhkan interaksi dengan sumber belajar, khususnya interaksi yang sifatnya manusiawi yaitu sifat individu yang kolaboratif (Wasis, 2010).

Sumber belajar dalam hal ini bisa berupa buku atau pendidik. Fungsi pendidik akan berubah ke arah pendidik sebagai pengelola pembelajaran. Fungsi pendidik yaitu merancang penyediaan sumber-sumber belajar agar belajar menjadi lebih mudah, lebih cepat, lebih menarik, dan lebih menyenangkan (Wasis, 2005). Pendidik dapat melaksanakan pembelajaran baik secara online maupun tradisional. Walther (1996) menyatakan bahwa pembelajaran online mempunyai karakteristik komunikasi yang unik terutama komunikasi asyncronous yang cenderung komunikasi tingkat tinggi.

Brook et all (2006) menyatakan bahwa pembelajaran yang berbasis web saja tidak cukup berhasil melaksanakan tujuan pembela-jaran, 
Barokati, dkk., Pengembangan Pembelajaran Berbasis Blended Learning pada Mata Kuliah...

karena memiliki kelemahan dalam penilaian pedagogik, pengajaran, dan psikologi.

Hendri (2009) menyatakan bahwa pengembangan pembelajararan blended berbasis web platform opensource Matakuliah Teknologi Pembelajaran S1 Jurusan Teknologi Pembelajaran Universitas Negeri Malang dapat digunakan dalam Matakuliah lainya, dengan catatan melakukan evaluasi menyeluruh serta dukungan kebijakan pada implementasi pembelajaran. Blended learning telah diterapkan di Institut Teknologi Bandung (ITB) dalam 2 tahun ini dan berhasil mengembangkanya untuk mendukung program pembelajaran yang berkualitas. Universitas Negeri Semarang juga telah mengembangkan pembelajaran berbasis Blended learning dan memakai situs e-Learning berbasis internet untuk menunjang kegiatan akademik (http://ilmo.unnes.ac.id). Proses pembelajaran Blended learning juga telah dikembangkan di Eropa Akademi Online (EOA) bekerjasama dengan Jean Monnet-Ketua Ilmu Politik Universitas Cologne dan mitra lainnya untuk program pascasarjana pada program studi Ilmu Humaniora dan Ilmu Sosial di Uni Eropa Studi Online (http: www. masterstudies.co.id).

Dalam penelitian akan dikembangkan pembelajaran yang menggabungkan antara e-learning dengan komposisi (50\%) dengan tradisional $(50 \%)$ menggunakan media online yaitu web dan media offline yaitu media presentasi power point, tatap muka, serta buku panduan sebagai petunjuk penggunaan dalam pembelajaran yang berguna untuk memudahkan pemahaman pelajar.

Berdasarkan hasil observasi terhadap mahasiswa S1 Pendidikan Matematika Fakultas Keguruan dan Ilmu Pendidikan di Universitas Islam Darul Ulum Lamongan, pada 22 Juli 2013 ditemukan bahwa mahasiswa kurang antusias dalam mengikuti perkuliahan di samping itu mata kuliah Komputer Pemrograman materinya syarat dengan teori. Untuk mengatasi permasalahan ini, maka perlu dikembangkan model pembelajaran yang menarik, efektif, dan efisien. Berdasarkan uraian di atas, maka peneliti perlu mengembangkan model pembelajaran blended learning untuk mahasiswa S1 FKIP UNISDA Lamongan pada Matakuliah Komputer Pemrograman.

Penelitian ini diharapkan dapat membuka peluang untuk menghadirkan sejumlah manfaat, antara lain sebagai bahan masukan bagi dosen dalam rangka mengembangakan pembelajaran Komputer Pemrograman, guna membantu kelancaran mahasiswa dalam perkuliahan dan sebagai bahan pertimbangan bagi dosen dalam rangka membuat rancangan pembelajaran Komputer Pemrograman yang sesuai dengan konsep yang dikembangkan oleh universitas.

\section{METODOLOGI}

Metodologi yang digunakan dalam penelitian ini adalah pembelajaran berbasis blended, analisa karakteristik mata kuliah yang akan diterapkan untuk implementasi E-Learning serta pembuatan desain website E-Learning.

Tabel 1. 1 Model-model Pembelajaran

\begin{tabular}{|c|c|c|}
\hline $\begin{array}{l}\text { Persentase Bahan } \\
\text { Ajar Berbasis } \\
\text { Web }\end{array}$ & Model & Deskripsi \\
\hline $0 \%$ & Tradisional & $\begin{array}{l}\text { Pembelajaran tanpa memanfaatkan fasilitas online Perangkat } \\
\text { pembelajaran dibawa dikelas dan pembelajaran berbasis tatap } \\
\text { muka }\end{array}$ \\
\hline $1-29 \%$ & Web facilitated & $\begin{array}{l}\text { Pemanfaatan web dalam proses pembelajaran untuk membantu } \\
\text { peningkatan pe guasaan bahan ajar yang tidak terpenuhi dalam } \\
\text { proses tatap muka (pemberian materi tambahan melalui web) } \\
\text { Pemanfaatanya lebih banyak pada pengumpulan tugas }\end{array}$ \\
\hline $30-79 \%$ & Blended & $\begin{array}{l}\text { Proses pembelajaran yang menggunakan kombinasi antara } \\
\text { bahan ajar berbasis web dan tatap muka. Porsi pembelajaran } \\
\text { online lebih besar dari tatap muka. Dalam proses pembelajaran, } \\
\text { interaksi (forum diskusi) lebih banyak dilakukan }\end{array}$ \\
\hline $100 \%$ & $\begin{array}{l}\text { On-line atau } \\
\text { elearning }\end{array}$ & $\begin{array}{l}\text { Seluruh proses pembelajaran melalui online. Tidak ada pembela- } \\
\text { jaran tatap muka }\end{array}$ \\
\hline
\end{tabular}




\subsection{Pembelajaran Berbasis Blended}

Secara konsep, pengembangan model blended learning didasarkan pada model pembelajaran menurut Srisakdi (2006), dalam buku pedoman pengembangan bahan ajar berbasis Web terbitan Departemen Pendidikan nasional, membagi model pembelajaran secara umum menjadi empat kelompok. Seperti dapat dilihat pada Tabel 1.

Pada pengembangan pembelajaran berbasis blended dipakai hitungan dalam satu semester ada 5 bulan efektif, maka masa tatap muka dilakukan dalam 2 hingga 3 minggu. Sisa 4 bulan 1 minggu mahasiswa akan belajar mandiri dengan pembelajaran berbasis web dan ujian semester. Dalam masa belajar mandiri (4 bulan 1 minggu), mahasiswa akan berkumpul dan bertemu beberapa kali dengan dosen di web atau bertemu langsung sesuai jadwal yang telah ditentukan. Proses tatap muka ditujukan untuk memfasilitasi setiap permasalahan yang dihadapi mahasiswa selama proses belajarnya. Pengembangan blended juga mengarah pada bahan ajar yang digunakan. Bahan ajar yang digunakan salah satunya berupa modul dalam kemasan elektronik. Dalam pembelajaran blended, selain bahan ajar modul elektronik, dalam proses belajarnya mahasiswa juga memanfaatkan bahan ajar berbasis web.

Pengembangan bahan ajar yang lain adalah pemanfaatan media atau teknologi merupakan salah satu ciri dalam proses pembelajaran berbasis web, diantaranya pemanfaatan teks, audio, video, dan multimedia adalah untuk pengayaan matari untuk berlatih dan untuk penguatan mahasiswa dalam mempelajari salah satu topik.

Metode pembelajaran yang digunakan adalah metode pembelajaran mandiri dan metode pembelajaran kolaborasi yang menggunakan fasilitas teknologi informasi dan komunikasi. Strategi interaksi dalam pengembangan pembelajaran blended memiliki dasar ragam obyek belajar dalam setiap babak pembelajaran, dirancang dan ditentukan pola interaksi atau strategi belajar yang dapat ditempuh mahasiswa.

Interaksi dalam pengembangan pembelajaran berbasis Blended learning pada matakuliah Komputer Pemrograman FKIP UNISDA berfungsi membantu mahasiswa belajar, melalui beragam alur yang dipilihnya. Agar interaksi dalam pengembangan pembelajaran menggunakan model Blended learning bisa efektif, maka interaksi tersebut perlu dirancang dengan cermat oleh pengembang atau dosen. Objek belajar dapat di peroleh dosen dari kumpulan bahan ajar yang dimilikinya untuk pembelajaran tatap muka dan nantinya akan dikombinasikan dengan powerpoint, atau juga mencari di internet. Pengembangan pembelajaran model blended mengedepankan bagaimana terjadi komunikasi antara sumber belajar dan pebelajar melalui teknologi komunikasi web. Teknologi komunikasi yang diharapkan mampu menjembatani setiap orang untuk saling berkomunikasi secara cepat dalam jarak yang jauh sekalipun. Media komputer dan jaringan sangat berperan dalam memudahkan hubungan, baik hubungan personal, organisasi atau dalam tingkat yang lebih luas lagi. Untuk memenuhi semua kebutuhan pembelajaran dengan berbagai karakteristik maka pendekatan melalui blended learning adalah yang paling tepat.

Blended learning memungkinkan pembelajaran menjadi lebih profesional untuk menangani kebutuhan belajar dengan cara yang paling efektif dan efisien serta memiliki daya tarik yang tinggi (Wasis, 2010). Keuntungan yang diperoleh dengan manfaat pembelajaran berbasis blended learning bagi lembaga pendidikan sangat banyak seperti yang telah dikembangkan oleh Universitas Negeri Semarang yang disebut ILMO (Increasing Learning Motivation) merupakan situs eLearning berbasis internet.

\subsection{Karakteristik Mata Kuliah Komputer Pemrograman}

Mata kuliah Komputer Pemrograman adalah mata kuliah yang masuk dalam kelompok mata kuliah dasar pada fakultas keguruan dan ilmu pendidikan. Mata kuliah ini biasanya diprogram pada semester 4 dengan bobot satuan kredit semester (SKS) dan jam semester adalah 3. Mata kuliah ini adalah mata kuliah wajib bagi mahasiswa fakultas keguruan dan ilmu pendidikan (Pedoman Studi Universitas Islam Darul Ulum Lamongan, 2005).

Berdasarkan paparan diatas, terdapat tiga tujuan umum pembelajaran yang diharapkan dikuasai oleh mahasiswa adalah:

1. Mahasiswa mampu memahami konsep, teori dan praktek Komputer Pemrograman,

2. Mahasiswa mampu memiliki pandangan secara teknis komputer terhadap fenomena pendidikan yang terjadi dalam masyarakat,

3. Mahasiswa mampu menganalisis masalah lembaga pendidikan dan pelaku pendidikan menggunakan komputer sebagai alat bantu. 
Barokati, dkk., Pengembangan Pembelajaran Berbasis Blended Learning pada Mata Kuliah...

Tabel 2. Manfaat ILMO

\begin{tabular}{|c|c|}
\hline Menyusun Silabi & $\begin{array}{c}\text { Mengakses Informasi } \\
\text { dan } \\
\text { Materi Perkuliahan }\end{array}$ \\
\hline $\begin{array}{l}\text { Mengunggah materi } \\
\text { perkuliahan }\end{array}$ & $\begin{array}{l}\text { Mengunduh materi } \\
\text { perkuliahan }\end{array}$ \\
\hline Memberikan tugas & Melakukan transaksi \\
\hline kepada mahasiswa & tugas-tugas perkuliahan \\
\hline $\begin{array}{l}\text { Menerima pekerjaan } \\
\text { mahasiswa }\end{array}$ & Mengerjakan tugas \\
\hline Membuat tes/quiz & Mengerjakan tes/quiz \\
\hline Memberikan nilai & $\begin{array}{l}\text { Melihat pencapaian } \\
\text { hasil belajar }\end{array}$ \\
\hline $\begin{array}{l}\text { Memonitor keaktifan } \\
\text { mahasiswa }\end{array}$ & Melihat kehadiran \\
\hline $\begin{array}{l}\text { Mengolah nilai } \\
\text { mahasiswa }\end{array}$ & Melihat nilai \\
\hline $\begin{array}{l}\text { Berinteraksi dengan } \\
\text { mahasiswa dan } \\
\text { sesama dosen } \\
\text { melalui forum } \\
\text { diskusi dan chat. }\end{array}$ & $\begin{array}{l}\text { Berinteraksi dengan } \\
\text { sesama mahasiswa dan } \\
\text { dosen melalui forum } \\
\text { diskusi dan chat. }\end{array}$ \\
\hline
\end{tabular}

\subsection{Karakteristik Mahasiswa S1 Fakultas Keguruan dan Ilmu Pendidikan UNISDA Lamongan}

Mahasiswa FKIP UNISDA dari latar belakang yang berbeda namun jenjang yang sama yakni SMA, SMK, MA, dan dari jurusan yang berbeda-beda pula yakni Bahasa, IPA, dan IPS. Perbandingan jumlah mereka hampir sama, namun kemampuan akademik mereka berbedabeda. Secara umum kemampuan mereka dalam kategori sedang dan dari sisi motivasi serta kemandirian belajarnya masih perlu di tingkatkan.

Hal ini di dasarkan pada pengamatan lapangan secara langsung dan wawancara langsung dengan tim pengajar mata kuliah sosiologi pendidikan. Berdasarkan pengamatan secara langsung serta hasil wawancara dengan tim pengajar pada saat ini mata kuliah Komputer Pemrograman belum memiliki media pembelajaran sebagai pedoman dalam proses pembelajaran dalam perkuliahan. Mahasiswa lebih banyak mencatat materi yang disampaikan oleh dosen.

Menganalisis karakteristik pebelajar menurut Degeng (1997) adalah mengetahui ciri-ciri perseorangan pebelajar berupa bakat, kematangan tingkat berpikir, dan kemampuan tingkat awalnya.Berdasarkan analisis tersebut dapat dipilih dan dirancang pendekatan secara tepat.
Suparman (1997) juga menyatakan pentingnya mengetahui prilaku dan karakteristik awal mahasiswa, karena akan mempunyai implikasi terhadap penyusunan bahan ajar dan sistem instruksional. Lebih lanjut beliau menyebutkan ada dua pendekatan yang bisa dipilih. Pertama mahasiswa menyesuaikan dengan materi pelajaran dan pendekatan kedua adalah sebaliknya yakni materi pelajaran disesuaikan dengan mahasiswa.

\subsection{Desain Pembelajaran Model ADDIE}

Salah satu model untuk merrancang suatu pembelajaran adalah model ADDIE. Model ADDIE yaitu singkatan Analysis-Design-Development-Implementation-Evaluation, merupakan salah satu model yang menjadi pedoman dalam memgembangkan pembelajaran yang efektif, dinamis dan mendukung pembelajaran itu sendiri. Sehingga dapat membantu dosen dalam pengelolaan pembelajaran. ADDIE muncul pada tahun 1990-an yang dikembangkan oleh Raiser dan Mollenda.

Model pengembangan yang digunakan dalam penelitian ini adalah ADDIE (Analyze, Design, Develop, Implement, and Evaluate). Model ini mengarahkan penelitian pada optimalisasi proses untuk mengukur keluaran yang dapat diukur (LOT, 2001:4). Masing-masing tahapan dalam ADDIE merupakan langkah-langkah dasar yang penting dan selalu digunakan dalam mendesain pembelajaran, dengan penjelasan masing-masing tahapannya sebagai berikut:

a. Analyze (Analisa)

Menganalisa pebelajar (atribut, kebutuhan, dan karakteristik), biaya, alternatif penyampaian, keterbatasan, waktu pembelajaran berakhir, dan kinerja yang diharapkan dapat ditampilkan pebelajar di akhir pembelajaran (Powers, 1997).

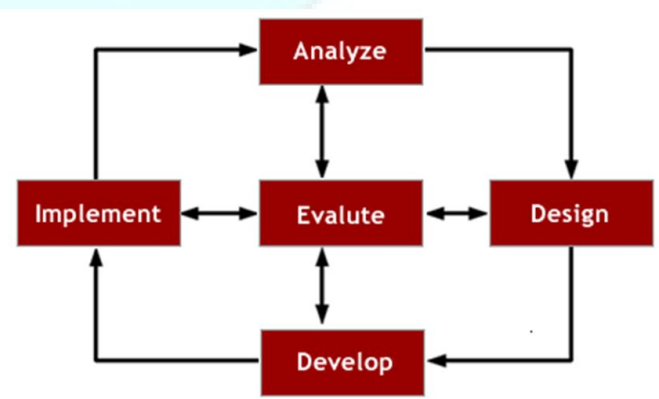

Gambar 1 Elemen Inti Model Desain Pembelajaran ADDIE Sumber: Reiser \& Dempsey (2002:18) 
b. Design (Rancangan)

Memilih tatanan atau latar pembelajaran online yang sesuai untuk mengembangkan kemampuan kognitif pebelajar yang sesuai dengan tujuan pembelajaran (Driscoll, 1998:50). Merumuskan tujuan khusus atau indikator, memilih pendekatan yang dilakukan, tata letak, dan nilai rasa program, panduan, pelajaran, dan modul (Hall, 1997:231). Merancang isi pembelajaran yang secara khusus digunakan dengan perantara elektronik/internet (Porter, 1997:127).

c. Develop (Pengembangan)

Menyediakan atau menciptakan media yang dibutuhkan, memberdayakan keunggulan internet untuk menyajikan informasi dalam berbagai bentuk media sehingga sesuai dengan karakteristik pebelajar (Porter, 1997:196). Merumuskan jenis interaksi yang sesuai, sehingga dapat memacu pebelajar untuk kreatif, inovatif, dan ingin belajar lebih banyak lagi (Porter, 1997:200). Merencanakan aktifitas yang memungkinkan kelompok pebelajar mengkonstruk dukungan lingkungan sosial (Simonson et al, 2000:115).

d. Implement (Penerapan)

Kegiatan yang dilakukan dalam tahapan ini meliputi: Penggandaan dan pendistribusian materi yang diperlukan, menyiapkan alternatif kegiatan jika terjadi masalah teknis (Simonson et al, 2000:115).

e. Evaluate (Evaluasi)

Melakukan tes sesuai dengan standar pembelajaran.

\section{HASIL dan PEMBAHASAN}

Dalam mempersiapkan penelitian atau riset, dibutuhkan data pembuktian bagi pemecahan persoalan. Penelitian akan berhasil dan berjalan lancar sesuai dengan tujuan dan waktu yang telah ditentukan, jika diadakan persiapanpersiapan yang berhubungan dengan usaha untuk memperoleh data.

\subsection{Model Pengembangan}

Salah satu model pengembangan media yang memperhatikan tahapan-tahapan dasar desain pengembangan media yang sederhana dan mudah dipahami adalah model ADDIE. Menurut Molenda (2003), Model ADDIE adalah istilah sehari-hari yang digunakan untuk menggambarkan pendekatan sistematis untuk pengembangan pembelajaran. ADDIE merupakan singkatan yang mengacu pada proses-proses utama dari proses pengembangan system pembelajaran, yaitu: Analysis (analisis), Design (desain), Development (pengembangan), Implementation (implementasi), dan Evaluation (evaluasi).

\subsection{Prosedur Pengembangan}

Prosedur pengembangan pembelajaran berbasis blended matakuliah Komputer Pemrograman ini mengikuti tahapan-tahapan model ADDIE yang sudah ada. Model ini menggunakan 5 tahapan pengembangan yakni:

1) Analisis

Tahap analisis terdiri dari dua tahap, yaitu:

- Analisis kinerja (performance analysis), pengembang menganalisis keterampilan, pengetahuan dan motivasi belajar mahasiswa pada proses pembelajaran.

- Analisis kebutuhan (need analysis), pada langkah ini pengembang menganalisis kebutuhan dan permasalahan, yaitu berupa materi yang relevan, buku ajar, strategi pembelajaran, motivasi belajar, dan kondisi belajar.

2) Desain

Pada langkah ini pengembang merekayasa model pembelajaran berbasis blended learning sedemikian rupa dengan merumuskan tujuan pembelajaran baik umum maupun khusus. Selanjutnya mengembangkan butir-butir tes atau soal yang digunakan untuk mengukur tingkat kemajuan siswa dan tingkat pencapaian tujuan yang telah dirumuskan. Dan terakhir mengembangkan strategi pembelajaran. Pengembangan pembelajaran berbasis Blended learning juga didesain dengan memperhatikan prinsip-prinsip desain pesan agar dapat menarik perhatian siswa.

3) Pengembangan Pengembangan berupaya menyusun dan merekayasa model pembelajaran berdasarkan informasi yang telah diperoleh dari berbagai tahap sebelumnya. Pengembang memodifikasi model yang telah ada berupa web, powerpoint, panduan operasional mahasiswa dan dosen, serta menentukan model dan strategi pembelajaran yang disesuaikan dengan karakteristik mahasiswa dan blended learning.

4) Implementasi

Pada langkah ini pembelajaran berbasis blended learning divalidasi terlebih dahulu kepada para ahli, yakni ahli isi, ahli desain, dan ahli media pembelajaran. Setelah mendapat validasi atau dinyatakan layak sebagai media pembelajaran, maka uji coba akan dilakukan pada uji coba perorangan, kelompok kecil dan lapangan. 
Barokati, dkk., Pengembangan Pembelajaran Berbasis Blended Learning pada Mata Kuliah...

5) Evaluasi

Pada langkah ini pengembang melakukan klarifikasi data yang didapat dari angket berupa tanggapan dari mahasiswa, serta terhadap kompetensi, pengetahuan, keterampilan, dan sikap yang harus dimiliki mahasiswa pada mahasiswa FKIP UNISDA Lamongan setelah mengikuti kegiatan pembelajaran.

\subsection{Uji Coba Produk}

Pembelajaran berbasis penggabungan (blended) pada matakuliah Komputer Pemrograman merupakan matakuliah yang memberikan kemampuan kepada mahasiswa agar dapat mengetahui konsep pemrograman dipandang dari perspektif pendidikan. Materi perkuliahan lebih bersifat mengkonstruksi pengetahuan dan pengalaman mahasiswa. Pada pembelajaran mandiri dengan menggunakan web pembelajaran yang dapat diakses melalui intranet ini (http://localhost/moodle) mahasiswa dapat selalu memantau sewaktu-waktu karena dosen akan memberikan pengumuman tugas di dalam forum. Mahasiswa juga dibekali panduan penggunaan serta panduan pembelajaran sehingga mahasiswa dapat mempersiapkan diri untuk melakukan pembelajaran mandiri di dalam web pembelajaran (Gambar 3).

Uji coba produk dimaksudkan untuk mengumpulkan data yang dapat dipergunakan sebagai dasar untuk menetapkan tingkat keefektifan, keefesienan, dan atau daya tarik produk yang dihasilkan (PPKI UM, 2010). Bagian ini meliputi: 1) desain ujicoba; 2) subyek uji coba; 3) jenis data; 4) instrument pengumpulan data; dan 5) teknik analisis data. Seperti yang terlihat pada Gambar 2.

Data yang telah dikumpulkan dibagi menjadi dua bagian, yaitu: 1) tiga data dari evaluasi pertama, berupa data hasil review ahli, isi, ahli media, dan ahli desain, 2) dua data dari hasil dosen dan mahasiswa. Data tersebut diperoleh dari hasil review berupa tanggapan langsung pada angket dari ahli isi, ahli media, dan ahli isi, ahli desain, dosen pengampuh mata kuliah dan mahasiswa.

Instrumen yang dipergunakan untuk mengumpulkan data adalah angket. Angket dipergunakan untuk pengumpulan data dari subjek uji coba untuk keperluan perbaikan. Angket bersifat tertutup dan terbuka. Angket tertutup disediakan untuk reviewer dalam memberikan penilaian terhadap produk pengembangan pembelajaran berbasis blended yang telah dikembangkan. Sedangkan angket bersifat terbuka disediakan untuk reviewer dalam memberikan saran yang tidak disediakan pilihannya dalam angket tertutup.

Teknik analisis data yang dipergunakan untuk mengolah data dari hasil tinjauan ahli dan uji coba pengembangan pada pengembangan pembelajaran berbasis blended yaitu menggunakan analisis statistik diskriptif dan analisis diskriptif kualitatif.

\section{SIMPULAN dan SARAN}

Bab penutup pada produk pengembangan pembelajaran berbasis blended pada matakuliah Komputer simpulan dan saran terhadap produk pengembangan.

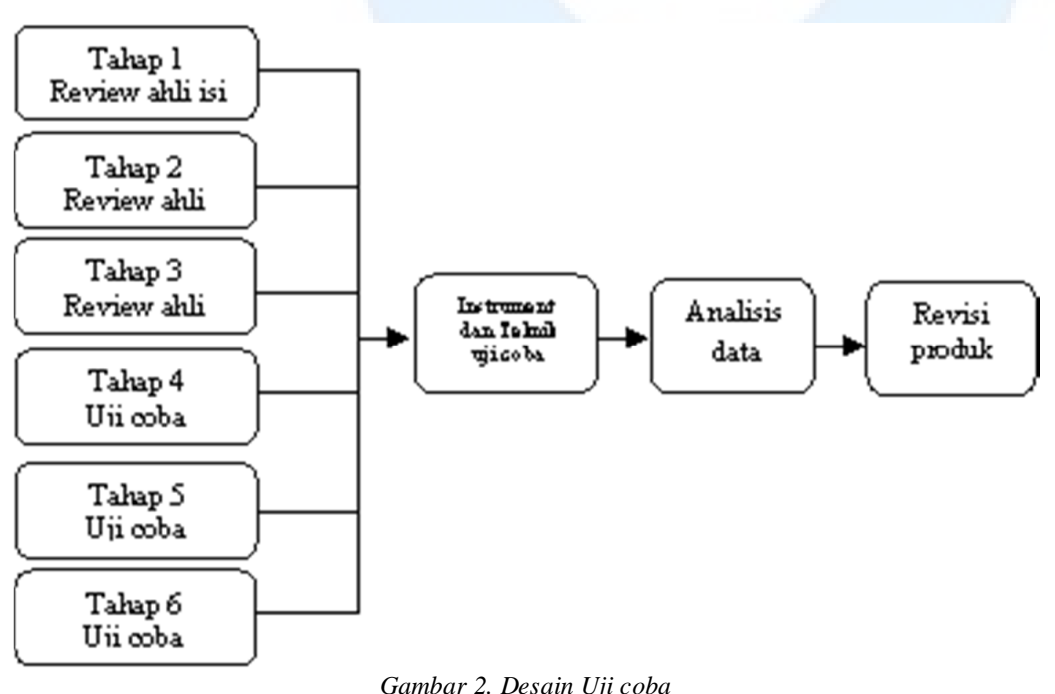

Gambar 2. Desain Uji coba 
Tabel 3. Hasil Kuesioner Terbuka

\begin{tabular}{|c|c|c|c|c|c|c|c|c|c|c|c|c|c|}
\hline \multirow{3}{*}{ Responden } & \multicolumn{13}{|c|}{ Efektivitas } \\
\hline & \multicolumn{3}{|c|}{ Teknologi } & \multicolumn{3}{|c|}{ Desain } & \multicolumn{3}{|c|}{ Tujuan } & \multicolumn{4}{|c|}{ Isi/Konten } \\
\hline & $\mathbf{1}$ & 2 & 3 & 4 & 5 & 6 & 7 & 8 & 9 & 10 & 11 & 12 & 13 \\
\hline 1 & 4 & 4 & 4 & 4 & 4 & 4 & 4 & 4 & 4 & 4 & 4 & 4 & 4 \\
\hline 2 & 5 & 5 & 5 & 5 & 5 & 5 & 5 & 5 & 5 & 5 & 5 & 5 & 5 \\
\hline 3 & 3 & 3 & 4 & 3 & 3 & 3 & 4 & 5 & 4 & 5 & 5 & 4 & 4 \\
\hline 4 & 4 & 4 & 4 & 4 & 4 & 4 & 4 & 4 & 4 & 4 & 4 & 4 & 4 \\
\hline 5 & 5 & 5 & 5 & 5 & 5 & 5 & 5 & 5 & 5 & 5 & 5 & 5 & 5 \\
\hline 6 & 4 & 4 & 4 & 4 & 4 & 4 & 4 & 4 & 4 & 4 & 4 & 4 & 4 \\
\hline 7 & 4 & 4 & 4 & 4 & 4 & 4 & 4 & 4 & 4 & 4 & 4 & 4 & 4 \\
\hline 8 & 5 & 5 & 5 & 5 & 5 & 5 & 5 & 5 & 5 & 5 & 5 & 5 & 5 \\
\hline 9 & 5 & 5 & 5 & 5 & 5 & 4 & 4 & 4 & 4 & 4 & 4 & 4 & 4 \\
\hline 10 & 4 & 4 & 4 & 4 & 4 & 4 & 4 & 4 & 4 & 4 & 4 & 4 & 4 \\
\hline 11 & 5 & 5 & 5 & 5 & 5 & 5 & 5 & 5 & 5 & 5 & 5 & 5 & 5 \\
\hline 12 & 4 & 4 & 4 & 4 & 4 & 4 & 4 & 4 & 4 & 4 & 4 & 4 & 4 \\
\hline 13 & 5 & 5 & 5 & 5 & 5 & 5 & 5 & 5 & 5 & 5 & 5 & 5 & 5 \\
\hline 14 & 4 & 4 & 4 & 4 & 4 & 4 & 4 & 4 & 4 & 4 & 4 & 4 & 4 \\
\hline 15 & 5 & 5 & 5 & 5 & 5 & 5 & 5 & 5 & 5 & 5 & 5 & 5 & 5 \\
\hline 16 & 5 & 5 & 5 & 3 & 3 & 3 & 3 & 4 & 3 & 3 & 3 & 3 & 3 \\
\hline 17 & 5 & 5 & 5 & 5 & 5 & 5 & 5 & 5 & 5 & 5 & 5 & 5 & 5 \\
\hline 18 & 4 & 4 & 4 & 4 & 4 & 4 & 4 & 4 & 4 & 4 & 4 & 4 & 4 \\
\hline 19 & 5 & 5 & 5 & 5 & 5 & 5 & 5 & 5 & 5 & 5 & 5 & 5 & 5 \\
\hline 20 & 4 & 4 & 4 & 4 & 4 & 4 & 4 & 4 & 4 & 4 & 4 & 4 & 4 \\
\hline 21 & 5 & 5 & 5 & 5 & 5 & 5 & 5 & 5 & 5 & 5 & 5 & 5 & 5 \\
\hline 22 & 5 & 5 & 5 & 5 & 5 & 5 & 5 & 5 & 5 & 5 & 5 & 5 & 5 \\
\hline 23 & 4 & 4 & 3 & 4 & 4 & 4 & 4 & 4 & 4 & 4 & 4 & 4 & 4 \\
\hline 24 & 4 & 4 & 4 & 3 & 4 & 4 & 3 & 3 & 3 & 3 & 3 & 3 & 3 \\
\hline 25 & 5 & 5 & 5 & 5 & 5 & 5 & 5 & 5 & 5 & 5 & 5 & 5 & 5 \\
\hline 26 & 5 & 5 & 5 & 5 & 5 & 5 & 5 & 5 & 5 & 5 & 5 & 5 & 5 \\
\hline 27 & 4 & 4 & 4 & 4 & 4 & 4 & 4 & 5 & 4 & 4 & 4 & 4 & 4 \\
\hline 28 & 4 & 4 & 4 & 4 & 4 & 4 & 4 & 4 & 4 & 4 & 4 & 4 & 4 \\
\hline 29 & 5 & 5 & 5 & 5 & 5 & 5 & 5 & 5 & 5 & 5 & 5 & 5 & 5 \\
\hline 30 & 4 & 4 & 4 & 4 & 4 & 4 & 4 & 4 & 4 & 4 & 4 & 4 & 4 \\
\hline$\%$ indikator & 0,89 & & & 0,88 & & & 0,88 & & & 0,66 & & & \\
\hline$\%$ total & 0,88 & & & & & & & & & & & & \\
\hline
\end{tabular}

Simpulan yang bisa diambil dari penelitian adalah:

a. Kesimpulan pembelajaran memberikan gambaran bahwa pembelajaran berbasis blended yang dikembangkan memberikan kontribusi pada pengembangan pembelajaran di FKIP UNISDA Lamongan dan dapat direspon positif oleh mahasiswa sebagai pengguna (adanya penilaian mahasiswa sebesar $88,29 \%$ ).

b. Kegiatan pembelajaran baik tatap muka, online maupun offline menunjukkan respon yang baik oleh pengguna.
Saran yang diharapkan mampu untuk meningkatkan kualitas penelitian adalah:

a. Dalam pelaksanaan pengembangan pembelajaran berbasis blended menggunakan produk pembelajaran berupa media presentasi dan web sebaiknya dilakukan secara seimbang antara kegiatan tatap muka, online maupun offline.

b. Mahasiswa diharuskan membaca panduan pembelajaran, dengan membaca panduan pembelajaran mahasiswa dapat mengerti tentang petunjuk penggunaan serta kompetensi yang diharapkan setelah proses pembelajaran selesai. 
Barokati, dkk., Pengembangan Pembelajaran Berbasis Blended Learning pada Mata Kuliah...

\section{DAFTAR RUJUKAN}

Barroso, J. \& Cabranes, Gómez. 2009. Face to Face Learning Methodologies vs Distance Learning Methodologies: Case Study Online using Qualitative Analysis. International Conference of Multimedia and ICT in Education

Degeng, I, N.S, 1997, Strategi pembelajaran Mengorganisasi Isi Dengan Model Elaborasi, Disertai Bahasan Tentang Temuan Penelitian, Malang, IKIP Malang \& Ikatan Profesi Teknologi Pendidikan Indonesia.

Dwiyogo Wasis D, 2010. Pembelajaran berbasis blended learning. Makalah disajikan dalam seminar dan lokakarya peningkatan kualitas pembelajaran melalui blended learning model, PPS IKIP Malang: tidak diterbitkan

LOT. 2001. Addie: Instructional Design Model. (online). http://hab.wikispaces.com/file/view/addie.p

df. Diakses pada 30 September 2011. Texas: College Station.

Molenda, M. 2003. Educational Technology: An Encyclopedia. Santa Barbara: A. Kovalchick \& K. Dawson, Ed's

Powers. 1997. Addie: Instructional Model. (online).

http://metalab.uniten.edu.my/ iskandar/proj ect/july\%2009/ADDIE.pdf. Diakses pada 30 September 2011.

Pramono. Y. B. H. 1996. Pembelajaran Berbantuan Komputer dalam Pokok Bahasan Present Perfect Tense Matakuliah Structure II pada program Pendidikan Bahasa Inggris FKIP Universitas Widya Mandala Surabaya. Tesis PPS IKIP Malang: Tidak Diterbitkan.

Reisser, Robert A \& Dempsey, John V. 2002.Trends and Issues in Instructional Design and Technology. New Jersey: Pearson Education. Inc. 